\title{
Audiologists should not fail with falls: A call to commit to prevention of falls in older adults
}

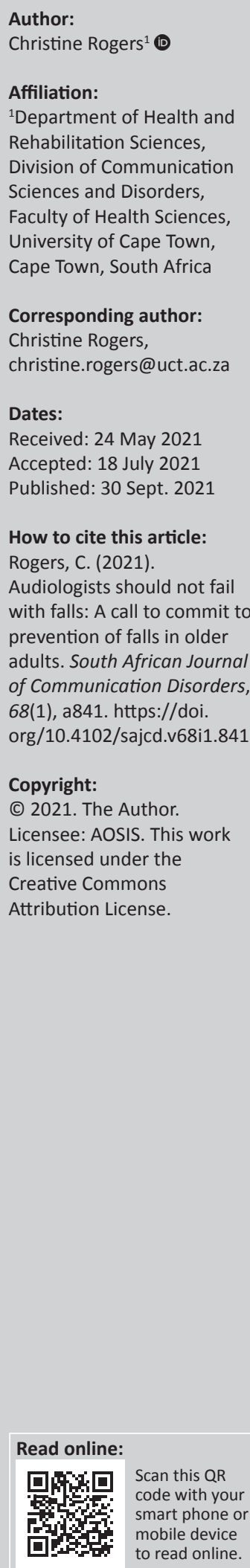

Globally, falls are a serious economic and public health concern. While all age groups are impacted by falls, the threats to morbidity and mortality are most severe in older adults. Recent literature has linked hearing loss, and related issues such as an increase in sedentary behaviour, to a greater risk of falls. Therefore, this opinion article aims to raise audiologists' awareness of falls in ageing patients or clients, and calls for change in terms of having these rehabilitation professionals embrace identification and management of fall risk.

Keywords: falls; fall prevention; fall risk; older adults; hearing impairment; audiology.

Population ageing is arguably one of the most significant social transformations of the 21st century with direct and obvious implications to healthcare and health policy:

\begin{abstract}
.. Ageing, of course, is inevitable and older people are more likely to have multiple, coexistent, and interrelated health problems. This fact, together with geriatric syndromes, frailty and impaired cognition, continence, gait, and balance, suggests the need for a more thorough 'retooling' of the healthcare system and workforce to meet the health challenge of ageing. (Stucki, Bickenbach, Gutenbrunner, \& Melvin, 2018, p. 309) (Italicised by author)
\end{abstract}

Globally, falls are a serious economic and public health concern (Haddad, Bergen, \& Florence, 2019). Injurious falls present a significant morbidity and mortality threat to the lifespan from early infancy (Alonge \& Hyder, 2014) to young, middle (Verma et al., 2016) and late adulthood (Shen et al., 2017). A fall describes an individual unintentionally and involuntarily moving towards the ground or other lower level (Lima, Ricci, Nogueira, \& Perracini, 2018), which is not the result of a major intrinsic event or hazard (Lamb, Jørstad-Stein, Hauer, \& Becker, 2005). Intrinsic events are idiosyncratic health-related issues, such as visual acuity or balance deficits (Gazibara et al., 2017), which may include age, sex and ethnicity (Kosma, 2014). This opinion article aims to raise audiologists' awareness of falls in ageing patients or clients and calls for change in terms of identifying and addressing the risk of falls.

Falls are an important clinical concern for older adults, associated with increased morbidity and mortality rates, as well as having major implications for public health (Gazibara et al., 2017). As the world's population ages, the rate of falls is growing disproportionally. The ranking of fall-related deaths has increased over some decades, with the World Health Organisation (WHO) confirming that falls are the second leading cause of deaths and unintentional injury deaths after road traffic accidents worldwide (WHO, 2018). In the United States of America, falls are the predominant cause of injury across almost all ages (Timsina et al., 2017). An older adult in America falls every second, requires emergency services for fall-related injuries every $18 \mathrm{~s}$ with a fall-linked death being reported every 20 minutes (CDC, 2016). Low-and-middle-income countries are neither spared the phenomenon of injurious falls nor ageing. Data from 17 countries across four different income rankings suggest that falls are associated with rural settings, increasing age, ${ }_{1}^{1}$ female sex and current or previous alcohol use (Raina et al., 2016). In South Africa, alcohol represents a significant health and social problem, with one of every three adults consuming alcohol and one in seven binge drinking (Vellios \& Van Walbeek, 2018). Intrinsic fall risk factors already described, some of which are linked to social determinants of health, combine with environmental hazards, such as poor infrastructure in public places, and should result in placing falls firmly on the agendas of rehabilitation professionals.

\section{Relevance of falls to audiologists Hearing loss is linked to falls}

As humans age, sensorineural hearing loss (presbycusis) develops (Nordvik et al., 2018). Meta-analysis has suggested that hearing loss established with pure tone audiometry results in an 1.Note the referenced study only considered ages between 30 and 70 years. 
almost seven-fold increased risk of falling (Jiam, Li, \& Agrawal, 2016). Other correlates of hearing impairment in older adults relevant to an increased fall risk include sedentary behaviour, slower gait speed (Shayman, Earhart, \& Hullar, 2017), social isolation and withdrawal (Criter \& Honaker, 2013), and cognitive decline (Rutherford, Brewster, Golub, Kim, \& Roose, 2017). With an ageing population, the number and rate of individuals seeking audiology services will increase (Criter \& Honaker, 2016). Thus, audiologists have extensive access to older adults, and are in a pivotal position to screen for falls and associated risk factors. Despite the opportunity for audiologists to act as gatekeepers for identifying the risk of falls in their hearing-impaired patients, disappointingly in practice, at least in the United States of America, less than one-third attempt any form of screening (Criter \& Honaker, 2017).

\section{Holistic balance assessment}

Historically, audiologists had a role in assessing vestibular integrity, likely because of the location of the end organs in the inner ear and correlations between labyrinthine disorders, which may affect both hearing and balance. Internationally, increasing numbers of audiologists are involved in the assessment and management of patients with vestibular dysfunction (Nelson, Akin, Riska, Andresen, \& Mondelli, 2016). In South Africa, services include audiological assessments, clinical and instrumented vestibular evaluations, and vestibular rehabilitation therapy (Seedat, Khoza-Shangase, \& Sebothoma, 2018).

Professional scope of audiology mandates that virtually all physical outcome measures related to fall risk assessment would be included. More advanced testing, for example, using the MiniBESTest to explore the different constructs of balance and fall risk (Magnani et al., 2020), would require more in-depth training and some experience. In 2011, South African audiology degree training programmes were directed to include vestibular management as an exit level outcome (HPCSA, 2018). Notwithstanding the necessity for graduate professionals to have skills in vestibular management, audiologists in South Africa have been slow to embrace vestibular practice (Seedat et al., 2018). It is possible that by starting with a small but patientvalued service, such as screening older adults for fall risk, professional confidence could be built, and audiologists would be inspired to engage more fully in this critical area.

\section{Dizziness and vertigo increase fall risk}

Dizziness and vertigo are common complaints reported in older populations (Hall \& Meldrum, 2016), some of whom consult an audiologist, who may function either in a team of professionals or as the sole provider. Numerous researchers have described the link between vestibular deficits and falls. For example, a case-control study reported that $80 \%$ of older adults with clinically significant vestibular impairment fell (Liston et al., 2014). Even if participants' symptoms of dizziness had settled because of compensatory processes, their fall risk remained elevated (Liston et al., 2014). Another study of patients with vestibular impairment and associated dizziness suggested an increased risk of falls by a factor of 12.3 (Allen, Ribeiro, Arshad, \& Seemungal, 2017). Overall, these and other studies support the view that audiologists should be questioning all older adults regarding falls, not just those who complain of dizziness. Indeed, it is argued that because of the predictability of falls, failing to evaluate older adults' risk of fall is a significant neglect in the duty of care to audiology patients.

\section{Calls for agency and change}

The key roles of an audiologist include disease prevention and health promotion activities at all levels of healthcare. Decades ago, calls were made for audiologists to concern themselves with the 'balance' system rather than purely vestibular function and evaluation (Jacobson, 2001). Leaders such as Jacobson and other audiologists continue to remind us to embrace balance and fall issues; however seemingly, little progress has been made in changing the clinical practice of audiologists.

A directive for audiologists performing vestibular assessments with American Medicare beneficiaries to conduct fall risk assessment and formulate plans of care (Bassett \& Honaker, 2016) offers a glimmer of hope. However, much work remains to encourage more widespread adoption of plans for fall prevention and health promotion activities within our profession. Indeed, the focus in emerging regions needs to shift from curative services to health promotion at all ages and levels of care.

\section{Moving towards rehabilitation}

The profession experiences a challenge because audiologists do not necessarily embrace rehabilitation (Hull, 2018) as do other professionals, such as physio- and occupational therapists (Babatunde, MacDermid, \& MacIntyre, 2017). Current practice has a diagnostic focus, rather than deeply engaging with patients and building strong therapeutic alliances (Hull, 2018). There is convincing evidence that vestibular rehabilitation is effective in managing symptoms of vestibular deficits (Dunlap, Holmberg, \& Whitney, 2019). Thus, programmes based on vestibular rehabilitation and applied in a fall prevention context could be argued to be relevant to audiologists and their patients. Moreover, many effective exercise-based fall prevention programmes exist, with compelling evidence to support them. Here, audiologists can play a role by discussing the impact of hearing loss and its associated sedentary behaviour and withdrawal, raising awareness in their patient populations and encouraging physical activity (PA) and appropriate referral to community resources. More detailed strategies are discussed in the following section.

\section{Steps audiologists should implement to identify and manage fall risk}

The second part of this opinion article suggests simple strategies for audiologists to identify and manage fall risk amongst older adult patients or clients. 


\section{Prescribe activity}

Interestingly, a large number of research studies on fall risk focus on factors that are not responsive to therapeutic interventions, for example, chronological age and sex. Otherwise, attention is directed to medical management like medication review. Issues such as activity-based strategies for fall risk management have received less attention. For example, few authors have examined sedentary behaviour (as previously observed, associated with both ageing and hearing loss) and found that challenging this lifestyle with PA is a potentially treatable cause of falls (Thibaud et al., 2012). Thibaud et al. (2012) considered the role of PA and falls by meta-analysis. The results revealed that for older adults, PA is a protective factor for falls, particularly injurious falls. Physical activity may address intrinsic risk factors for falls by improving balance and gait speed, muscular and physical strength. Therefore, PA should be recommended in the management of fall risk. Furthermore, Cochrane reviews have addressed multiple interventions to fall risk, including exercise-based fall prevention programmes, with evidence in favour of the latter (Gillespie et al., 2012; Sherrington et al., 2019). A systematic review by Sherrington et al. (2020) was undertaken to inform the WHO guidelines on PA and sedentary behaviour, which re-affirmed the value of exercise, particularly balance-related activities including Tai Chi, to reduce the risk of falls in older adults (Sherrington et al., 2020). If audiologists are empowered with quality information, they are better informed to educate their older adult populations.

\section{Screen for fall risk}

Numerous instruments exist to screen for falls and fall risk. Ideally, previous falls, fear of falling, and the number of prescribed medications should be ascertained and noted along with the age and sex of the patient. Polypharmacy is the simultaneous use of multiple drugs by an individual and is present in approximately half of all older adults from high-income countries (Morin, Johnell, Laroche, Fastbom, \& Wastesson, 2018). There is little reason to believe that the narrative is any different in South Africa (Saka, Oosthuizen, \& Nlooto, 2019). Thresholds for the number of medications that constitute polypharmacy vary but are usually between three and six (Gutiérrez-Valencia et al., 2018). There are increasing links between polypharmacy, falls and the onset of frailty (GutiérrezValencia et al., 2018; Wastesson, Morin, Tan, \& Johnell, 2018). Fear of falling may occur despite no recent fall and is a powerful risk factor for future falls, likely because of self-restriction and cautious gait (Auais et al., 2017; Denkinger, Lukas, Nikolaus, \& Hauer, 2015; Lavedán et al., 2018). Fear of falling may in fact be enabling if an older adult is willing to explore strategies to address the fear, such as embarking on an exercise programme. A fall reported within the previous year similarly increases the risk of another fall, and thus, helpful information is obtained from simple questioning (Lusardi et al., 2017).

\section{Physical outcome measures for falls}

There are four tests suitable for everyday clinical practice that have evidence to support them (Lusardi et al., 2017). These include the Timed Up and Go (TUG) test, which will be discussed here, the Five Times Sit to Stand Test, Single Leg Stance Test and preferred walking speed; however, more research studies are required to definitively link them to fall risk. Briefly, the TUG test requires an individual to get up from a chair, walk $3 \mathrm{~m}$ around a traffic cone, return and sit down again. Several balance-related activities are required, such as transitioning from sitting to standing, changing direction around an obstacle and ambulation. The test is timed, and ageand sex-matched normative data are available (Bohannon, 2006; Ibrahim, Singh, \& Shahar, 2017; Pondal \& Del Ser, 2008). The TUG is recommended for primary care by the American and British Geriatric Societies (Smith et al., 2016), and can be administered quickly and efficiently. Variations for the TUG exist (manual and cognitive) and have promise for refining fall risk. Individuals whose result (time to complete TUG in seconds) falls outside the Centers for Disease Control and Prevention's (CDC) $12 \mathrm{~s}$ cut-off should be considered at risk of falls and referred appropriately. A copy of the test procedure can be downloaded from https://www.cdc.gov/steadi/pdf/ TUG_test-print.pdf.

\section{Manage holistically}

Consider referral back to the primary care provider with the results of the audiological assessment, which might suggest an increased risk of falls. Steps such as medication review may be advisable. Clinical assessment of vestibular function, falls history and risk, and balance and gait (either with an audiologist with a special interest or a physiotherapist) could be indicated. Resources such as the CDC's Stopping Elderly Accidents, Deaths and Injuries (STEADI) programme are helpful (https://www.cdc.gov/steadi/index.html) and provide information for patients and healthcare professionals. Checklists to manage potential fall hazards at home are appreciated by patients and their families alike and are freely available on the internet. Call systems in case of falls are useful for older adults who live alone. Finally, a pamphlet demonstrating how to get up after a fall (e.g. see https: / / www.stayonyourfeet.com.au/wp-content/ uploads/2016/01/SOYF-Up-Off-the-Floor-knees-v1-lowres. pdf) or a video link can be empowering if patients practice how to get up safely after a fall.

\section{Conclusion}

Audiologists have multiple roles, including being rehabilitation professionals, enhancing disease prevention and health promotion activities, and being advocates of change. First, compelling evidence exists to support that exercise is 'medicine' (Sallis, 2009), with the implication that all healthcare professionals should be prescribing it. Second, the case for exercise and PA to reduce the risk of falls is strong. Specific to fall risk, which is enhanced by factors such as ageing and hearing loss, audiologists are ideally 
situated as gatekeepers and should be an additional entry point to management of older adult populations with falls. Screening for falls is simple and quick, even in constrained settings; however, the impact of falls is life-changing for individuals who fall and their families. As Africa greys, let us embrace our role and start identifying and managing the risk of fall amongst the older adult populations!

Until the great mass of the people shall be filled with the sense of responsibility for each other's welfare, social justice can never be attained. (Keller, 1914)

\section{Acknowledgements Competing interests}

The researcher has previously acted as a consultant to a medical communications company and prepared continuing professional development materials for their client, a naturopathic company. She has previously consulted for an equipment manufacturer and produced newsletters for management of dizzy patients on behalf of the company. She has not been involved in marketing any equipment for that company. The researcher has and continues to work as a consultant or an expert witness for several insurance companies, specifically the Insurance Ombudsman of South Africa. Appearances at congresses as an invited speaker have been paid for by congress secretariats or funded from the researcher's personal research funds. None of these roles present a conflict of interest.

\section{Author's contributions}

The author declares that she is the sole author of this article.

\section{Ethical considerations}

This article followed all ethical standards for research without any direct contact with human or animal subjects.

\section{Funding information}

This research work was supported in part by the National Research Foundation of South Africa (Grant No. 110802) and the Harry Crossley Fellowship, 2017, University of Cape Town.

\section{Data availability}

Data sharing is not applicable to this article as no new data were created or analysed in this study.

\section{Disclaimer}

The views and opinions expressed in this article are those of the author and do not necessarily reflect the official policy or position of any affiliated agency of the authors.

\section{References}

Allen, D., Ribeiro, L., Arshad, Q., \& Seemungal, B.M. (2017). Age-related vestibular loss: Current understanding and future research directions. Frontiers in Neurology, 7, 231. https://doi.org/10.3389/fneur.2016.00231
Alonge, O., \& Hyder, A.A. (2014). Reducing the global burden of childhood unintentional injuries. Archives of Disease in Childhood, 99(1), 62-69. https://doi. org/10.1136/archdischild-2013-304177

Auais, M., French, S., Alvarado, B., Pirkle, C., Belanger, E., \& Guralnik, J. (2017). Fear of falling predicts incidence of functional disability two years later: A perspective from an international cohort study. The Journals of Gerontology: Series A, 73(9), from an international cohort study. The Journals of

Babatunde, F., MacDermid, J., \& MacIntyre, N. (2017). Characteristics of therapeutic alliance in musculoskeletal physiotherapy and occupational therapy practice: A alliance in musculosketetal physiotherapy and occupational therapy practice: A
scoping review of the literature. BMC Health Services Research, 17(1), 375. https://doi.org/10.1186/s12913-017-2776-0

Bassett, A.M., \& Honaker, J.A. (2016). Audiologist's role within the changing climate of fall prevention: Are we ready? Perspectives of the ASHA Special Interest Groups, 1(8), 4-13. https://doi.org/10.1044/persp1.SIG8.4

Bohannon, R.W. (2006). Reference values for the timed up and go test: A descriptive meta-analysis. Journal of Geriatric Physical Therapy, 29(2), 64-68. https://doi. org/10.1519/00139143-200608000-00004

CDC. (2016). Falls are leading cause of injury and death in older Americans. Retrieved from https://www.cdc.gov/media/releases/2016/p0922-older-adult-falls.html

Criter, R.E., \& Honaker, J.A. (2013). Falls in the audiology clinic: A pilot study. Journal of the American Academy of Audiology, 24(10), 1001-1005. https://doi. org/10.3766/jaaa.24.10.11

Criter, R.E., \& Honaker, J.A. (2016). Audiology patient fall statistics and risk factors compared to non-audiology patients. International Journal of Audiology, 55(10), 564-570. https://doi.org/10.1080/14992027.2016.1193235

Criter, R. E., \& Honaker, J. A. (2017). Fall risk screening protocol for older hearing clinic patients. International Journal of Audiology, 56(10), 767-774. https://doi.org/10. 1080/14992027.2017.1329555

Denkinger, M.D., Lukas, A., Nikolaus, T., \& Hauer, K. (2015). Factors associated with fear of falling and associated activity restriction in community-dwelling older adults: A systematic review. American Journal of Geriatric Psychiatry, 23(1), 72-86. https://doi.org/10.1016/j.jagp.2014.03.002

Dunlap, P.M., Holmberg, J.M., \& Whitney, S.L. (2019). Vestibular rehabilitation: Advances in peripheral and central vestibular disorders. Current Opinion in Neurology, 32(1), 137-144. https://doi.org/10.1097/WCO.0000000000000632

Gazibara, T., Kurtagic, I., Kisic-Tepavcevic, D., Nurkovic, S., Kovacevic, N., Gazibara, T., \& Pekmezovic, T. (2017). Falls, risk factors and fear of falling among persons older than 65 years of age. Psychogeriatrics, 17(4), 215-223. https://doi.org/10.1111/ psyg.12217

Gillespie, L.D., Robertson, M.C., Gillespie, W.J., Sherrington, C., Gates, S., Clemson, L.M., \& Lamb, S.E. (2012). Interventions for preventing falls in older people living in the community. The Cochrane Database of Systematic Reviews, $2012(9)$, CD007146.

Gutiérrez-Valencia, M., Izquierdo, M., Cesari, M., Casas-Herrero, Á., Inzitari, M., \& Martínez-Velilla, N. (2018). The relationship between frailty and polypharmacy in older people: A systematic review. British Journal of Clinical Pharmacology, 84(7), 1432-1444. https://doi.org/10.1111/bcp.13590

Haddad, Y.K., Bergen, G., \& Florence, C. (2019). Estimating the economic burden related to older adult falls by state. Journal of Public Health Management and Practice, 25(2), E17-E24. https://doi.org/10.1097/PHH.0000000000000816

Hall, C.D., \& Meldrum, D. (2016). The aging vestibular system: Implications for rehabilitation. In G.P. Jacobson \& N.T.T. Shephard (Eds.), Balance function assessmet and management (2nd ed., pp. 793-808). San Diego, CA: Plural Publishing Inc.

Honaker, J. (2021). Fall prevention: Patient-centered outcomes. ASHA Leader Live. Retrieved from https://leader.pubs.asha.org/do/10.1044/2021-0222-fall-riskprevention/full/

HPCSA. (2018). Statement regarding special licensing vestibular practice. Retrieved from https://www.hpcsa.co.za/Uploads/SLH/Policy\%20and\%20Guidelines/ statement_regarding_special_licensing_vestibular3_1208\%20(2).pdf

Hull, R.H. (2018). Aural rehabilitation: What's in a name? The Hearing Journal, 71(1), 40-43. https://doi.org/10.1097/01.HJ.0000529849.31742.a6

Ibrahim, A., Singh, D.K.A., \& Shahar, S. (2017). 'Timed up and go' test: Age, gender and cognitive impairment stratified normative values of older adults. PLOS One 12(10), e0185641. https://doi.org/10.1371/journal.pone.0185641

Jacobson, G.P. (2001). Assessing the risk of falls in the elderly: Above and beyond the ENG. The Hearing Journal, 54(6), 10-12. https://doi.org/10.1097/01 HJ.0000294232.08871.72

Jiam, N.T.L., Li, C., \& Agrawal, Y. (2016). Hearing loss and falls: A systematic review and meta-analysis. The Laryngoscope, 126(11), 2587-2596. https://doi.org/10.1002/ lary. 25927

Keller, H. (1914). Out of the Dark. Retrieved from https://libquotes.com/helen-keller/ quote/lbq607z

Kosma, M. (2014). An expanded framework to determine physical activity and falls risks among diverse older adults. Research on Aging, 36(1), 95-114. https://doi. org/10.1177/0164027512469215

Lamb, S.E., Jørstad-Stein, E.C., Hauer, K., \& Becker, C. (2005). Development of a common outcome data set for fall injury prevention trials: The prevention of falls network Europe consensus. Journal of the American Geriatric Society, 53(9), 1618-1622. https://doi.org/10.1111/j.1532-5415.2005.53455.x

Lavedán, A., Viladrosa, M., Jürschik, P., Botigué, T., Nuín, C., Masot, O., \& Lavedán, R. (2018). Fear of falling in community-dwelling older adults: A cause of falls, a consequence, or both? PLoS One, 13(3), e0194967. https://doi.org/10.1371/ journal.pone.0194967 
Lima, C.A., Ricci, N.A., Nogueira, E.C., \& Perracini, M.R. (2018). The Berg balance scale as a clinical screening tool to predict fall risk in older adults: A systematic review. Physiotherapy, 104(4), 383-391. https://doi.org/10.1016/j.physio.2018.02.002

Liston, M.B., Bamiou, D.-E., Martin, F., Hopper, A., Koohi, N., Luxon, L., \& Pavlou, M. (2014). Peripheral vestibular dysfunction is prevalent in older adults experiencin multiple non-syncopal falls versus age-matched non-fallers: A pilot study. Age and Ageing, 43(1), 38-43. https://doi.org/10.1093/ageing/aft129

Lusardi, M.M., Fritz, S., Middleton, A., Allison, L., Wingood, M., Phillips, E., ... Chui, K.K. (2017). Determining risk of falls in community dwelling older adults: A systematic review and meta-analysis using Posttest Probability. Journal of Geriatric Physical Therapy, 40(1), 1-36. https://doi.org/10.1519/JPT.0000000000000099

Magnani, P.E., Genovez, M.B., Porto, J.M., Zanellato, N.F.G., Alvarenga, I.C., Freire, Jr. R.C., \& De Abreu, D.C.C. (2020). Use of the BESTest and the Mini-BESTest for fall risk prediction in community-dwelling older adults between 60 and 102 years of age. Journal of Geriatric Physical Therapy, 43(4), 179-184, https://doi. 000000236

Morin, L., Johnell, K., Laroche, M.-L., Fastbom, J., \& Wastesson, J.W. (2018). The epidemiology of polypharmacy in older adults: Register-based prospective cohor study. Clinical Epidemiology, 10, 289-298. https://doi.org/10.2147/CLEP.S153458

Nelson, M.D., Akin, F.W., Riska, K.M., Andresen, K., \& Mondelli, S.S. (2016). Vestibula assessment and rehabilitation: Ten-year survey trends of audiologists' opinions and practice. Journal of the American Academy of Audiology, 27(2), 126-140. https://doi.org/10.3766/jaaa.15035

Nordvik, Ø., Heggdal, P.O.L., Brännström, J., Vassbotn, F., Aarstad, A.K., \& Aarstad, H.J. (2018). Generic quality of life in persons with hearing loss: A systematic literature review. BMC Ear, Nose and Throat Disorders, 18(1), 1. https://doi.org/10.1186/ s12901-018-0051-6

Pondal, M., \& Del Ser, T. (2008). Normative data and determinants for the timed 'up and go' test in a population-based sample of elderly individuals without gait disturbances. Journal of Geriatric Physical Therapy, 31(2), 57-63. https://doi. disturbances. Journal of Geriatric Physical
org/10.1519/00139143-200831020-00004

Raina, P., Sohel, N., Oremus, M., Shannon, H., Mony, P., Kumar, R., ... Yusoff, K. (2016) Assessing global risk factors for non-fatal injuries from road traffic accidents and falls in adults aged 35-70 years in 17 countries: A cross-sectional analysis of the prospective urban rural epidemiological (PURE) study. Injury Prevention, 22(2), 92-98. https://doi.org/10.1136/injuryprev-2014-041476

Rutherford, B.R., Brewster, K., Golub, J.S., Kim, A.H., \& Roose, S.P. (2017). Sensation and psychiatry: Linking age-related hearing loss to late-life depression and cognitive decline. American Journal of Psychiatry, 175(3), 215-224. https://doi. org/10.1176/appi.ajp.2017.17040423

Saka, S.A., Oosthuizen, F., \& Nlooto, M. (2019). Potential inappropriate prescribing and associated factors among older persons in Nigeria and South Africa.
International Journal of Clinical Pharmacy, 41(1), 207-214. https://doi. org/10.1007/s11096-018-0770-1

Sallis, R.E. (2009). Exercise is medicine and physicians need to prescribe it! British Journal of Sports Medicine, 43(1), 3-4. https://doi.org/10.1136/bjsm.2008.054825

Seedat, T., Khoza-Shangase, K., \& Sebothoma, B. (2018). Vestibular assessment and management in adults: Current practice by South African audiologists. Hearing, Balance and Communication, 16(2), 88-100. https://doi.org/10.1080/21695717. 2018.1463757
Shayman, C.S., Earhart, G.M., \& Hullar, T.E. (2017). Improvements in gait with hearing aids and cochlear implants. Otology \& Neurotology, 38(4), 484-486. https://doi. org/10.1097/MAO.0000000000001360

Shen, Y., Tay, Y.C., Teo, E.W.K., Liu, N., Lam, S.W., \& Ong, M.E.H. (2017). 240 association between the elderly frequent attender to the emergency department and 30-day mortality: A retrospective study over 10 years. Annals of Emergency Medicine, 70(4), S96. https://doi.org/10.1016/j.annemergmed.2017.07.462

Sherrington, C., Fairhall, N., Kwok, W., Wallbank, G., Tiedemann, A., Michaleff, Z.A., ... Bauman, A. (2020). Evidence on physical activity and falls prevention for people aged 65+ years: Systematic review to inform the WHO guidelines on physical activity and sedentary behaviour. International Journal of Behavioral Nutrition and Physical Activity, 17(1), 144. https://doi.org/10.1186/s12966-020-01041-3

Sherrington, C., Fairhall, N.J., Wallbank, G.K., Tiedemann, A., Michaleff, Z.A., Howard, K., ... Lamb, S.E. (2019). Exercise for preventing falls in older people living in the community. Cochrane Database of Systematic Reviews, 1(1), CD012424.

Smith, M.L., Chaudhary, S., Nieb, S., Bayakly, R., Graham, K., \& Head, E. (2016). Commentary: Building the older adult fall prevention movement - Steps and lessons learned. Frontiers in Public Health, 4, 277. https://doi.org/10.3389/ fpubh.2016.00277

Stucki, G., Bickenbach, J., Gutenbrunner, C., \& Melvin, J. (2018). Rehabilitation: The health strategy of the 21st century. Journal of Rehabilitation Medicine, 50(4), 309-316. https://doi.org/10.2340/16501977-2200

Thibaud, M., Bloch, F., Tournoux-Facon, C., Brèque, C., Rigaud, A.S., Dugué, B., \& Kemoun, G. (2012). Impact of physical activity and sedentary behaviour on fall risks in older people: A systematic review and meta-analysis of observational studies. European Review of Aging and Physical Activity, 9(1), 5-15. https://doi. org/10.1007/s11556-011-0081-1

Timsina, L.R., Willetts, J.L., Brennan, M.J., Marucci-Wellman, H., Lombardi, D.A., Courtney, T.K., \& Verma, S.K. (2017). Circumstances of fall-related injuries by age and gender among community-dwelling adults in the United States. PLoS One, 12(5), e0176561. https://doi.org/10.1371/journal.pone.0176561

Vellios, N., \& Van Walbeek, C. (2018). Self-reported alcohol use and binge drinking in South Africa: Evidence from the National Income Dynamics Study, 2014-2015. South African Medical Journal, 108(1), 33-39. https://doi.org/10.7196/ SAMJ.2017.v108i1.12615

Verma, S.K., Willetts, J.L., Corns, H.L. Marucci-Wellman, H.R., Lombardi, D.A., \& Courtney, T.K. (2016). Falls and fall-related injuries among community-dwelling adults in the United States. PLoS One, 11(3), e0150939. https://doi.org/10.1371/ journal.pone.0150939

Wastesson, J.W., Morin, L., Tan, E.C., \& Johnell, K. (2018). An update on the clinical consequences of polypharmacy in older adults: A narrative review. Expert Opinion on Drug Safety, 17(12), 1185-1196. https://doi.org/10.1080/14740338.2018.154 6841

WHO. (2018). Falls fact sheet 344. Retrieved from http://www.who.int/mediacentre/ factsheets/fs344/en/ 